\title{
A POSITIVE THEORY OF LEGISLATIVE INTENT
}

\author{
EDWARd P. SChWARTZ; Pablo T. SPILler," \\ AND SANTIAGO URBIZTONDO ${ }^{* *}$
}

\section{INTRODUCTION}

The ongoing debate about statutory interpretation has been profoundly affected by the introduction of social choice theory into the study of legal institutions. Prior to this development, legal scholars had relied on theories of civic virtue, arguments about judicial activism, and understandings of the Constitution to shape their debate. ${ }^{1}$ The first mention of Arrow's impossibility theorem and the subsequent chaos results proved quite a bombshell for this enterprise. ${ }^{2}$ As Judge Frank Easterbrook noted,

\begin{abstract}
Because legislatures comprise many members, they do not have "intents" or "designs" . . . It is not only impossible to reason from one statute to another but also impossible to reason from one or more sections of a statute to a problem not resolved. ... The existence of agenda control [within a legislature] makes it impossible for a court-even one that knows each legislator's complete table of preferences-to say what the whole body would have done with a proposal it did not consider in fact. ${ }^{3}$
\end{abstract}

In fact, one cannot rule out the possibility that, faced with filling a gap in a statute, the legislature would pass a provision clearly contrary to the provisions of the original statute.

Copyright @ 1994 by Law and Contemporary Problems

- Assistant Professor of Government, Harvard University.

* William B. McKinley Professor of Economics and Public Utilities, University of Illinois, Champaign-Urbana; Visiting Professor of Business and Public Policy, University of California, Berkeley.

**- Professor of Economics, Univesidad Nacional de la Plata, Argentina.

1. See generally William N. Eskridge, JR. \& PHILlip P. FRICKey, Cases and Materials on Legislation: STATUTES AND THE CREATION OF PUBliC POliCy (1988) (providing an excellent introduction to theories on statutory interpretation).

2. Arrow's theorem demonstrates that desirable characteristics of aggregating individual preference into societal choice are mutually inconsistent. These characteristics can be divided roughly into two categories: fairness and coherence. While majority rule is fair, it can lead to incoherence in the form of preference cycles (See Condorcet paradox). Legislative institutions can counter the incoherence, but only by empowering some individuals at the expense of others. That is, fairness must be sacrificed. See generally KENNETH J. ARROW, SOCIAL CHOICE AND INDIVIDUAL VALUES (1963).

3. Frank H. Easterbrook, Statutes' Domain, 50 U. CHI. L. REv. 533, 547-48 (1983). See also INS v. Cardoza-Fonseca, 480 U.S. 421, 452-53 (1987) (Scalia, J., concurring). 
When news of the consequences of social choice theory reached legal scholars, they were understandably alarmed. Objections were loud and immediate. Judge Mikva criticized public choice as being so far from reality as to be useless for legal scholars. In his introduction to a symposium on law and public choice, he wrote, "Mathematics has always held a strong allure for many social scientists, ... [but] [d]espite its seductiveness, ... the postulates of mathematics usually provide only fools' gold for human problems." ${ }^{\text { Farber and }}$ Frickey, while not overtly hostile to the application of public choice to law in certain cases, were sufficiently distressed by its pessimistic message to publish a book devoted to showing the limitations of such an approach. ${ }^{5}$

The version of social choice that informs this legal scholarship fails to account for two phenomena that social choice theorists now recognize as important to the formation of public policy: institutions and information. Long before judges had discovered the foundations of social choice, social choice theorists had discovered the role of institutions in promoting stability of political outcomes. The resulting "New Institutionalism," or "Positive Political Theory" ("PPT"), focused on designing models that recognized that political decisions are not made in an institutional vacuum. Legislatures have political parties, committees, caucuses, recognition and agenda rules, and, finally, well-defined reversion points (status quos), all of which add to the predictability and stability of policy decisions. Judge Easterbrook suggested in the passage quoted above that the presence of agenda control makes it impossible to predict what would emerge from the legislative process. In fact, quite the converse is true. If an individual (or small group) controls the legislature's agenda, it becomes necessary only to predict what the agenda-setter will do in order to anticipate the legislative outcome. This leads to a more tractable social choice problem.

Politics is fraught with uncertainty. Office holders do not know with precision the preferences of other office holders on every issue. One can never fully anticipate how the personnel of any branch of government will change in the near future. Changes in the political environment lead to changes in the saliency of various issues for political actors. Rule changes may make certain types of policymaking more or less costly and time-consuming, often to an extent that is only fully understood after the changes have been in place for a long time. Policy outcomes, therefore, depend heavily on the transmission of information among political actors. ${ }^{6}$ Certainly, when the Supreme Court is attempting to anticipate congressional response to the possible outcomes of a case before it, the Justices must consider the preferences of the members of Congress on the issue, the likelihood that the subject matter of the case is important enough to Congress to warrant the time and expense associated with enacting corrective

4. Abner J. Mikva, Foreword, 74 VA. L. REV. 167, 176 (1988).

5. See Daniel A. Farber \& Philip P. Frickey, LaW and Public Choice: A Critical INTRODUCTION 6-11 (1991).

6. See KeITH KREHBIEL, INFORMATION AND LegisLative ORgANIZATION (1991) (providing an excellent treatment of informational issues in legislative politics). 
legislation, and how changes in the preferences of the electorate might affect either of the above. The Justices, however, will seldom have perfect information on any of these points. In fact, their uncertainty is likely to be great enough to call into question what course of action the Court should take.

PPT authors have optimistically presented some of their papers as models of statutory interpretation. ${ }^{7}$ These authors appear to have forgotten, however, where this enterprise began. Legal scholars first turned to social choice to discover what it could say about interpretation and its sister concept legislative intent. There is general agreement among legal scholars that when a statute is clear, and when the circumstances under which it was passed differ little from those of today, the Court can and should adhere to what is written in the statute. This is the first canon of statutory interpretation. ${ }^{8}$ This represents the trivial case, for in a world of absolute certainty, there is no need for interpretation. The question of statutory interpretation is interesting only in the presence of uncertainty. ${ }^{9}$ While the existing PPT models have made great strides in describing the bargaining game underlying Court/Congress interaction, all of the models are deterministic. ${ }^{10}$ Although they all model something interesting, it is not actually statutory interpretation. This article's model of Court/Congress interaction factors in uncertainty and portrays a Court that actually engages in interpretion of statutes and discovery of legislative intent.

Statutory interpretation is the act of Justices attempting to discover what legislatures intended statutes to accomplish. PPT suggests that, if attention is paid to the institutional features of the legislature, this can be accomplished. ${ }^{11}$ Equilibria exist, deals are struck, compromises are made, and statutes are enacted. This is not to suggest that statutory interpretation is not a very difficult task. Justices spend thousands of hours trying to discern what legislatures intended and what the congressional response to judicial decisions might be. This article contends that this task is difficult, not because Justices are poor social scientists or unable to compute, but because a large amount of uncertainty is embedded in the political process.

Another major tenet of PPT is that institutions are not historical accidents. Institutions are designed, modified, and maintained so as to further the goals of those individuals responsible for the institutions' forms. Justices have not been forced to consider legislative history and other supplementary material. They

7. See, e.g., William N. Eskridge, Jr. \& John Ferejohn, Making the Deal Stick: Enforcing the Original Constitutional Structure of Lawmaking in the Modern Regulatory State, 8 J.L. ECON. \& ORG. 165 (1992); Rafael Gely \& Pablo T. Spiller, A Rational Choice Theory of Supreme Court Statutory Decisions: With Applications to the Grove City and State Farm Cases, 6 J.L. EcoN. \& ORG. 263 (1990); Matthew D. McCubbins et al., Positive Canons: The Role of Legislative Bargains in Statutory Interpretation, 80 GEO. L.J. 705 (1991).

8. See generally ESKRIDGE \& FRICKEY, supra note 1.

9. McNollgast, Legislative Intent: The Use of Positive Political Theory in Statutory Interpretation, 57 LAW \& CONTEMP. PROBS. 3 (Winter 1994).

10. Pablo T. Spiller, Agency Discrection Under Judicial Review, 16 MATHEMATICAL AND COMPUTER MODELING 185 (1992).

11. See generally McCubbins et al., supra note 7. 
have chosen to do so. It may be concluded, therefore, that such behavior is beneficial to Justices. This article addresses why this might be so. In particular, it hypothesizes that by paying attention to legislative history, the Court points to a means by which Congress can reduce the Court's uncertainty about the preferences of Congress. Although Congress cannot resolve all uncertainty for the Court, it can take steps to signal the Court about its preferences and, consequently, about types of judicial decisions likely to provoke a congressional response. Providing a means for the transfer of this information is mutually beneficial for Congress and the Court.

Some legal scholars have criticized the attention paid by Justices to committee reports, floor debate, and comments in the Congressional Record because these proceedings have never been voted on by the full Congress. This article generally agrees that one should not look to these sources for the definition of the law; however, they should not be ignored as sources of insight into what might emerge as the law, in response to a judicial decision. Committee reports are important because Congress's organization provides significant agenda control to committees. In particular, committees can raise the cost of enacting legislation by gate-keeping. If a committee chairperson does not want a piece of legislation to be considered by Congress, he or she can simply sit on it, refusing to report it to the floor. The discharge procedures, which can force the reporting of a bill, are time-consuming and cumbersome. It is usually not worthwhile for a member to fight with a committee chairperson. In this article's model, the Court, in anticipating possible congressional reaction to a decision, is concerned, first and foremost, with how the relevant committee feels about the issue and how salient the issue is for that committee.

It is costly to produce detailed committee reports. Similarly, it is costly to engage in protracted floor debate. The fact that Congress is willing to spend scarce resources on these activities signals to the Court that the subject matter of the relevant legislation is important, and that the costs of enacting corrective legislation are small relative to the benefits of doing so. This helps to explain the attention paid by the Court to supplementary materials. It should be noted, however, that Justices often stress the need to look for any possible way to infer the meaning of the statute from the text of the statute. Justices suggest that the role of supplementary sources should always be secondary. ${ }^{12}$ This article's model conforms to this approach. In the model, legislative history indicates to a Justice that he or she should examine the statute more closely; judicial decisions that deviate too far from the intent of the statute may be overturned by corrective legislation. In some sense, then, the process of generating legislative history is more important than its content.

While the generation of supplementary legislative materials is costly, it is not nearly so costly as writing more specific statutes. In addition to the time and manpower necessary to produce the statutory language, it must be agreed upon

12. See EsKRIDGE \& FrICKEY, supra note 1. 
by the Congress, a process that becomes more precarious as legislation becomes more specific. Specificity is also a two-edged sword. As a statute becomes more specific, it may be interpreted to say less about contingencies for which it has not directly accounted. A more specific statute will likely provide a Justice with more, rather than less, fodder with which to support the interpretation of his or her choosing. ${ }^{13}$ In addition, a more specific piece of legislation only constrains judicial interpretation to the extent that Congress is willing to support that legislation in the future. Therefore, while drafting specific legislation may provide a more informative signal to the Court, in the sense that it is costlier than some alternatives, it is not apparent that it necessarily improves upon the "clear meaning" of the statute.

The signaling model that this article employs allows Congress to resolve the Supreme Court's uncertainty about two factors: (1) how salient the issue being considered is to Congress, and (2) how costly it will be for Congress to enact corrective legislation in response to an undesirable Court interpretation of a statute. Since only one method of signaling is available, Congress cannot resolve all uncertainty in both factors. That is, separating, when possible, will only be partial. Therefore, while it may be possible to distinguish a Congress that cares a great deal from one that cares only a little, it will never be possible to identify from Congress's signaling behavior exactly what type of Congress the Court is dealing with in all instances. In addition, since Congress can never be absolutely certain about the cost of enacting corrective legislation until forced to do so, some uncertainty about reversal costs will remain even if the Court has correctly identified the "type" of Congress it faces. A result of this uncertainty is that some cases will still be overturned by the Court, even when Congress successfully signals its type. This result certainly conforms with the empirical observation that, while rare, congressional overrides of Supreme Court decisions do occur.

The model indicates that for separation of types through signaling to occur, the cost of passing corrective legislation must be greater than, and positively correlated with, the cost of sending the signal (generating supplementary materials to the initial legislation). If reversal costs are lower than signaling costs, no Congress will ever signal because reversing undesirable Supreme Court decisions will always be a cheaper method of achieving the same (and sometimes better) policy objectives. It is intuitively appealing to consider the costs of drafting corrective legislation to be related to those of generating committee reports and engaging in floor debate. After all, many of the same resources are used in these activities. One inferred benefit of signaling is the avoidance of costs associated with enacting corrective legislation. If the costs of signaling are not positively related to the benefits of signaling, then those Congresses from whom the Court would like to receive a signal (those with low reversal costs)

13. Even Easterbrook recognizes the limited value of Congress being overly detailed in enumerating what contingencies fall under a statute's domain: "Statutes rarely contain anything like [an actual decision of Congress concerning the domain of its enactment] . . . in part because members of Congress know that zipper clauses in statutes just invite clever evasions." Easterbrook, supra note 3, at 537. 
would be those precisely for which it will not be worthwhile to signal due to the prohibitively high signaling costs.

A final word about signaling costs is in order. As with all signaling models, the cost of signaling in this model cannot be either prohibitively high or so low as to render the signal meaningless. As previously mentioned, there are many forms that the signal from Congress to the Supreme Court might take. Some are certain to be more costly than others. How costly a signal the Supreme Court should encourage will depend on the actual values of the other parameters in the model. Writing a very detailed initial statute seems the most costly signal that Congress can send. It may be noted that, for some Congresses, the cost of drafting a very specific initial statute will be prohibitively high, suggesting that some less costly signal is more appropriate. This conclusion runs contrary to the argument by strict constructionists that the Court should force Congress to draft very detailed legislation by refusing to examine anything but statutory wording when interpreting statutes.

\section{II}

\section{THE MODEL}

This section develops a very stylized signaling model describing the interaction between Congress and the Supreme Court ${ }^{14}$ that expands upon the positive approach to the Court initially developed by Gely and Spiller. ${ }^{15}$ The positive approach to Court-Congress interaction is based on two building blocks concerning the preferences of the players and the sequence of the game.

\section{A. Preferences and Reversal Costs}

To simplify the model, this article assumes a unicameral legislature and a single dimensional policy space, under the jurisdiction of a particular committee that may have control over the final disposition of the pending statute. Let $P$ represent the ideal policy on the relevant dimension of the pivotal member of Congress. $^{16}$ Let the preferences of this particular pivotal member of Congress

14. The extension of this framework to introduce the administrative agencies is left for future research.

15. See generally Gely \& Spiller, supra note 7. For further theoretical extensions of this approach, see Eskridge \& Ferejohn, supra note 7; John Ferejohn \& Charles Shipan, Congressional Influence in Bureaucracy, 6 J.L. ECON. \& ORG. 1 (1990); John Ferejohn \& Barry Weingast, A Positive Theory of Statutory Interpretation, 12 INT'L REV. L. \& ECON. 263 (1992); Gely \& Spiller, The Political Economy of Supreme Court Constitutional Decisions: The Case of Roosevelt's Court Packing Plan, INT'L REV. L. \& ECON. 45 (1992); Spiller, supra note 10; Pablo T. Spiller, Rationality, Decision Rules, and Collegial Courts, 12 INT'L REV. L. \& ECON. 186 (1992); Pablo T. Spiller \& Matthew Spitzer, Judicial Choice of Legal Doctrine, 8 J.L. ECON. \& ORG. 8 (1992); Pablo T. Spiller \& Rafael Gely, Congressional Control or Judicial Independence: the Determinants of U.S. Supreme Court Labor Decisions, 1949-88, 23 RAND J. ECON. 463 (1992).

16. This article expresses no view about the degree of control exercised by committees over outcomes on the floor. For the purpose of this analysis, however, it is only necessary to identify the pivotal member of Congress, who may be the median member of the relevant committee, the median member of the floor, or the median member of the majority party in the committee. While these 
be given by $U^{C}(x)=-\alpha|x-P|$, where $\alpha$ represents the marginal disutility that Congress gets from a change in the policy away from $P, x$ represents a particular policy in the policy dimension, and $P$ reflects the ideal point of the pivotal member of Congress. ${ }^{17}$ This situation is represented in Figure $1 .^{18}$

It is crucial to the model that there be some uncertainty about the preferences of the relevant member of Congress. Let $P$ be known, but assume $\alpha$ is a random variable, with equal probability of taking the value $\alpha_{L}$ or $\alpha_{H}$. Different values of the saliency variable $\alpha$ reflect the extent to which Congress cares about the particular policy issue. A high (low) value of $\alpha$ means that deviations away from $P$ bring substantial (minor) utility loss to the relevant members of Congress.

Congress not only legislates, but it also polices the Court. One way of policing is reversing the Court. ${ }^{19}$ Reversal, however, is costly for Congress. First, members of Congress have to put time, effort, and staff into drafting a bill. The more crowded the congressional agenda, the higher the shadow value of these scarce resources, and hence the higher the cost of reversing the Court. Similarly, the less cohesive the Congress, or the lower the power of the relevant committee, the more difficult it will be to draft the necessary legislation. Let the cost of reversing the Court be a continuous random variable, which is drawn from two distributions: $T_{H}^{*}$ and $T_{L}^{*}$, where $T_{j}^{*}=T_{j}+v, j=H, L$, each with the same probability of occurring, where $E v=0$. Let $F(v)$ and $f(v)$ represent the distribution and density functions of $v$, respectively. There are, then, two sources of uncertainty about $T$. First, the expected value of $T$ may be $T_{H}$ or $T_{L}$, each with equal probability. Furthermore, the actual reversal cost will usually differ from $T_{j}$ by a random variable $v^{20}$

The model portrays the Court as a self-interested, ideologically motivated institution, making decisions subject not necessarily to the traditional legal rules of precedent, but rather to the constraints imposed by the other institutions of government (in this case, Congress). This article additionally assumes that the

preference assumptions are clearly very strong, they are made exclusively for expositional simplicity. Similar results would be obtained with more complicated committee/floor interactions, but at the expense of increased notational and computational complexity.

17. For expositional simplicity this article will refer to the pivotal member of Congress as "Congress."

18. Figure 1 appears infra page 59.

19. William N. Eskridge, Jr., Overriding Supreme Court Statutory Interpretation Decisions, 101 YaLE L.J. 331 (1991) (containing an excellent empirical study of congressional reversal of judicial decisions). See also Pablo T. Spiller \& Emerson Tiller, Invitations to Override: Congressional Reversals of Supreme Court Decisions (1993) (unpublished manuscript, on file with authors) (containing an analysis of the Supreme Court's invitations to override).

20. Observe that the distribution of $v$ has to be such that $T_{L}+v>0$ for all $v$, as reversal costs cannot be non-positive. Additionally, these two sources of uncertainty are important. If knowing $T_{j}$ would give full information about reversal costs, then, in signaling models with separating equilibria, one would not observe any reversal of Supreme Court decisions. 
Court's preferences can be represented by $U^{S C}(x)=-|x-S C|$, where $S C$ represents the ideal point of the Court in the policy space. ${ }^{21}$

While the preferences of politicians generally reflect the interests of their constituencies, this is not the case for Supreme Court Justices, who are appointed for life, and thus do not feel the electoral pressure to adopt policies that favor particular interest groups. Supreme Court Justices's preferences, then, reflect their views of the world. That is, Justices are ideologically motivated, where "ideology" is broadly defined.

\section{B. The Sequence of the Game}

This article models the interaction between Congress and the Supreme Court as a sequential game, where at each stage each player rationally forecasts the future evolution of the game and makes decisions accordingly. Thus, subgame perfection is assumed throughout. In general, our game has three stages: in the first stage, Congress learns its type $\left(\alpha_{\dot{p}} T_{j}\right)$ and passes an initial piece of legislation. As addressed below, this piece of legislation can be either specific or vague. ${ }^{22}$ In the second stage, the Supreme Court considers an agency implementation of the statute and makes a policy determination. ${ }^{23}$ In the third stage, Congress learns its actual reversal costs (that is, learns $v$ ) and considers whether to reverse the Court. Observe that when members of Congress pass the initial piece of legislation, they know only the expected reversal costs, that is, they know whether they are of a $T_{H}$ or $T_{L}$ type. Congress cannot know, however, what the actual cost of reversing the Court will be at reversal time. Thus, after the Court has made its decision, Congress learns its actual costs (that is, it learns v), ${ }^{24}$ and decides whether to reverse. If Congress reverses the Court, then the new piece of legislation, which must be quite specific, becomes the equilibrium to the game. If, however, Congress fails to reverse the Court, then the decision of the Court becomes the equilibrium to the game.

It is evident that if $T$ and $\alpha$ were perfectly known by the Court, then the model would be similar to previous models of Court/agency interaction where reversing agencies is costly, ${ }^{25}$ with Congress taking the place of the Court, and the Court taking the place of the agency. In particular, the Court would be restricted in its choice by the ability of Congress to overturn its decisions. In equilibrium, however, the Court's decision will never be overturned. Assume, for example, that $S C>P$, as in Figure 1. If the decision of the Court, $x_{s c}$, is higher

21. Observe that, without loss of generality, this article assumes that the marginal disutility of the Court is minus one.

22. It may be useful to think of specific legislation as being accompanied by supplementary materials.

23. This article assumes that the Court can make policy decisions on a continuum, rather than simply upholding or rejecting an agency decision. For an alternative model of judicial decisionmaking, see Gely \& Spiller, supra note 7; Pablo T. Spiller, Rationality, Decision Rules and Collegial Courts, 12 INT'L REV. L. \& ECON. 186 (1992).

24. It can be seen, then, that $v$ reflects the randomness inherent in the congressional agenda.

25. Spiller, supra note 10 . 
than $P+T / \alpha$, then the Court's decision will be reversed and substituted by legislation setting $P$ as the policy. Thus, if $S C>P$, then the optimal strategy for the Court is to set $x_{s c}=P+T / \alpha$. Given this decision, Congress will find it too costly to overturn the Court, and thus $x_{s c}$ becomes the final equilibrium.

As shown below in Figure 1, congressional reversals of Supreme Court decisions can occur when either $\alpha$ or $T$ are unknown.

\section{Figure 1}

\section{Representation of Preferences and Reversal Costs}

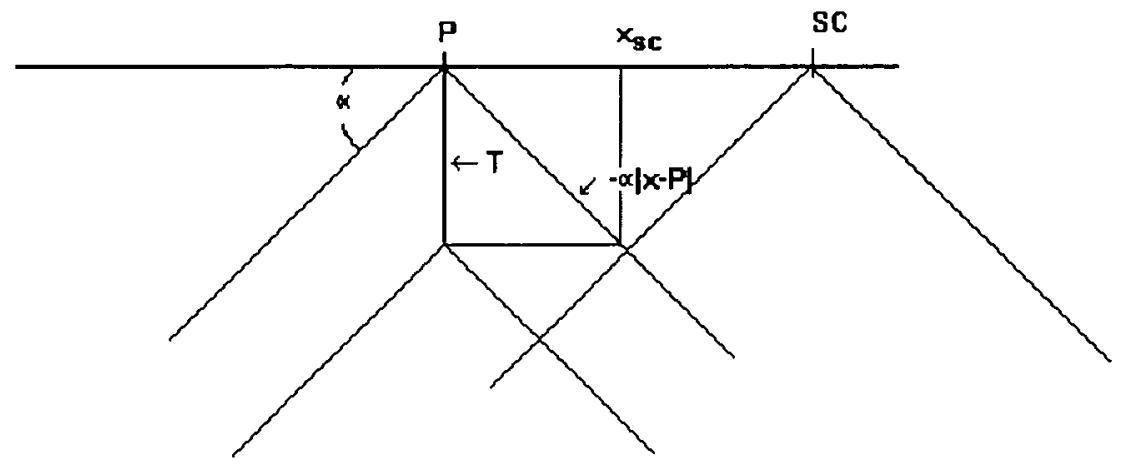

\section{The Specificity of Legislation}

When Congress passes legislation, it also decides on the form of its mandate. This article assumes that legislation can be of two types. It can be specific, providing the agencies and the Court with ample materials explaining the reasoning behind the statute and guidance for various contingencies, or it can be vague, providing the agencies with a policy goal to pursue but leaving the details of the implementation to the agencies. ${ }^{26}$ Examples of both types abound. Compare, for example, the Clean Air Act Amendments of $1970^{27}$ with their 1990 counterparts. $^{28}$ The initial legislation was vague, providing the EPA with substantial discretion on what it could do. On the other hand, the 1990 Amendments of the Clean Air Act are extremely detailed legislation. They

26. Various steps can be taken to increase specificity. Among them are more specific wording of the statute, extensive committee reports, and increased time for floor debate to be entered into the Congressional Record. This article treats all forms of specificity in the same manner.

27. Pub. L. No. 91-604, 84 Stat. 1676 (codified as amended in scattered sections of 42, 49, and 50 U.S.C.).

28. Pub. L. No. 101-549, 104 Stat. 2399 (1990) (codified as amended at 42 U.S.C. $\$ \S 7401-7671 q$ (West Supp. 1993)). 
consist of 300 plus pages of specific regulations (and exemptions), and provide the EPA with direct instructions on, for example, how to organize the market for pollution emissions.

This study models the degree of specificity as a binary variable: $S=\{1,0\}$, with $S=1$ signifying that Congress has made specific its goals. Observe, however, that being specific is also costly. As with the determinants of $T$, the cost of being specific is related to the cohesiveness of Congress, the fullness of the congression al agenda, and how much each member of Congress cares about the issue. In particular, for those members of Congress that care greatly about the issue (that is, those with high $\alpha$ ), passing a very specific piece of legislation actually provides them with benefits above and beyond the particular policy outcome. The passage of the law allows them to appear in the press and publicize their work for their constituents (who must also care deeply about the policy). On the other hand, for those who do not care at all about the issue (that is, those with low $\alpha$ ), appearing in press promoting this particular piece of legislation is detrimental, for their constituents would rightly infer that their representatives are spending time on a worthless activity. Observe that the first two determinants of the cost of specificity are the same as those determining $T$. Thus, for simplicity, let the cost of drafting specific initial legislation $(C(\bullet))$ be a general function of $T$ and $\alpha$, in particular, $C_{T}(T, \alpha)>0$, and $C_{\alpha}(T, \alpha)<0$. That is, signaling has lower net costs when Congress is passionate about the issue, and its organizational costs are low. Furthermore, this article assumes that for each type the costs of signaling are lower than the lowest feasible cost of reversal, that is, $C\left(T_{\dot{\nu}} \alpha_{j}\right)<T_{i}-\hat{v}$.

\section{The Advantages of Specific Legislation}

Why would members of Congress bother with specific and detailed legislation, if, as discussed above, it is costly? Why can they not just delegate to the relevant agency and the Court to enforce what they actually want? As is clear from the introductory discussion and the model above, if the Court knows perfectly Congress's preferences and the cost of reversing the Court, then there is a unique equilibrium which is independent of the nature of the initial legislation. $^{29}$ If, however, the Court lacks perfect knowledge of such, then writing specific legislation could provide a signal about the preferences and costs.

Consider, for example, a situation where the relevant members of Congress care greatly about the issue, and are, further, cohesive in their preferences (that is, they are $\left(\alpha_{H}, T_{L}\right)$ types). If they cannot signal to the Court their preferences and costs, then the Court will treat them as "average," both for their $\alpha$ 's and $T$ 's. Consequently, as will be apparent below, the optimal decision by the Court will be "too far" away from $P$, triggering too many reversals. Since reversal is

29. This article's assumption that the Court can make decisions on a continuum implies that the initial status quo plays no role. If the Court could only sustain or reverse an agency decision, then the status quo would play a role. Furthermore, if the initial legislation impacted upon the status quo, then there would be a role for specifying the initial legislation. 
expensive, there is a tradeoff between signaling ahead of time by writing a specific piece of legislation and reversing after the fact. Signaling, then, could provide the $\left(\alpha_{H}, T_{L}\right)$ type Congress with the possibility of achieving Court decisions closer to its ideal point, and hence the possibility of not having to reverse the Court too often.

The sending of such a signal by the $\left(\alpha_{H}, T_{L}\right)$ types, however, may not be productive. In particular, if members with low marginal disutilities or higher reversal costs could signal to the Court that they also have high $\alpha$ 's and low T's (that is, they mimic the $\left(\alpha_{H}, T_{L}\right)$ types), then the Court could not separate one type from the other. In this way, signaling by $\left(\alpha_{H}, T_{L}\right)$ types would not pay. Thus, there would be no signaling at all, and all legislation would be vague. ${ }^{30}$ Below, this article provides the conditions for these two types of scenarios (that is, separating and pooling) to arise.

\section{E. Solving the Model}

The authors solve the model in the following way. After looking at the optimal decision by the Court, given any particular information it has about Congress's preferences and reversal costs, the expected utility of writing a specific piece of legislation is then computed for each type of Congress. Writing a specific piece of legislation is not worthwhile unless by so doing Congress can change the Court's beliefs about Congress's preferences. In formal terms, only if the Court's posterior distribution of types is affected by the signaling will it pay for Congress to write a specific piece of legislation.

1. Complete Information About $\alpha$ and $\mathrm{T}$. This model begins by making some simplifying assumptions. First, let $P=0, S C>0$, and let $v$ be uniformly distributed in the range $[-\hat{v}, \hat{v}]$, with $f(v)=1 / 2 \hat{v} .{ }^{31}$ Thus, for a given Supreme Court decision $x_{s c}$, the probability that Congress will reverse it is given by the probability that the utility of Congress reversing the Court's decision, $-\left(T_{i}+v\right),{ }^{32}$ is higher than Congress's utility in not reversing the decision, $-\alpha x_{s c}{ }^{33}$ That is, $T_{j}+v$ has to be less than $\alpha x_{s c}$, or,

$$
\text { Prob }\left(\text { Reversall } x_{s c}, \alpha, T_{j}\right)=F\left(\alpha x_{s c}-T_{j}\right)=\left[\alpha x_{s c}-T_{j}+\hat{v}\right] / 2 \hat{v} \text {. }
$$

Given $x_{s c}$, and its corresponding reversal probability, the expected utility of the Supreme Court is given by:

$$
\begin{aligned}
E U^{s c}\left(x_{s c} \mid \alpha, T_{j}\right) & =F\left(\alpha x_{s c}-T_{j}\right) U^{s c}(P)+\left[1-F\left(\alpha x_{s c}-T_{j}\right)\right] U^{s c}\left(x_{\mathrm{sc}}\right) \\
& =-F\left(\alpha x_{s c}-T_{j}\right) x_{s c}+\left(x_{s c}-S C\right)
\end{aligned}
$$

30. Recall that, if sending a signal is more expensive than reversing, then no signaling will take place, and the policing of the Court would be done through congressional reversals.

31. Observe that since reversal costs cannot be negative, $T_{j}+v>0$ for all $v$ and $T_{j}$. Thus, since the minimum value of $v$ is $-\hat{v}, T>\hat{v}$ for all $T$.

32. If Congress reverses the Court, then it passes a piece of legislation that sets the policy equal to $P=0$. Thus, while it achieves its most desired policy utility, Congress incurs a utility loss equal to the cost of reversal: $-\left(T_{j}+v\right)$.

33. Since the ideal point of the Court is assumed to be higher than that of Congress, the Court will never make $x_{s c}<0$. 


$$
=x_{s c}\left(\hat{v}-\alpha x_{s c}+T_{j}\right) / 2 \hat{v}-S C,
$$

where (2c) is obtained from recalling that if $z$ is uniformly distributed in $[-\hat{v}, \hat{v}]$, then $F(z)=(z+\hat{v}) / 2 \hat{v}$.

The Supreme Court, then, maximizes its utility by picking a policy decision that will make a trade-off between a higher probability of reversal and a policy outcome closer to its most desired policy. ${ }^{34}$ The first order condition for the Court is given by

which, after rearranging, implies

$$
\partial E U^{s c}\left(x_{s c} \mid \alpha, T_{j}\right) / \partial x_{s c}=0,
$$

$$
x_{s c}^{*}=\left(\hat{v}+T_{j}\right) / 2 \alpha \text {. }
$$

Substituting (3) into (1) gives the equilibrium probability of reversal for a given $\alpha$ and $T_{j}$, as

$$
\operatorname{Prob}\left(\text { Reversall } x_{s c}, T_{j}\right)=3 / 4-T_{i} / 4 \hat{v}^{35}
$$

The equilibrium expected utilities of the Court and Congress can now be computed. Substituting (3) into (2) reveals that the equilibrium expected utility of the Court is given by

$$
E U^{* s c}\left(\alpha, T_{j}\right)=\left(\hat{v}+T_{j}\right)^{2} / 8 \alpha \hat{v}-S C
$$

while the equilibrium expected utility of Congress is given by:

$$
\begin{aligned}
& E U^{C}\left(x_{s c} \mid \alpha, T_{j}\right)=\int_{0}^{\alpha x_{\alpha}-T_{j}}-\left(T_{j}+v\right) f(v) d v+\int_{\alpha x_{x}-T_{j}}^{v}-\alpha x_{s c} f(v) d v \\
& =F\left(\alpha x_{s c}-T_{j}\right)\left(-T_{j}\right)-\int_{-\vartheta}^{\alpha x_{x}-T_{j}} v f(v) d v+\left(1-F\left(\alpha x_{s c}-T_{j}\right)\right)\left(-\alpha x_{s c}\right) \\
& =F\left(\alpha x_{s c}-T_{j}\right)\left[\alpha x_{s c}-T_{j}\right]-\alpha x_{s c}-\int_{-0}^{\alpha x_{\alpha}-T_{j}} v f(v) d v,
\end{aligned}
$$

which after substituting for the optimal $x_{s c}$ gives

$$
E U * C\left(\alpha, T_{j}\right)=\frac{\vartheta-14 T_{j}+\frac{T_{j}^{2}}{\hat{\vartheta}}}{16},
$$

where the * indicates that the expected utilities are equilibrium levels, given that the Court knows $\alpha$ and $T_{j}$.

Some preliminary results can now be expressed in the form of Lemma 1.

34. See Spiller, supra note 15.

35. Observe that since the probability of reversal has to be less than one, $F\left(\alpha x_{s c}-T\right)=\left(\alpha x_{s c}-T+\hat{v}\right) / 2 \hat{v}<1$. Since the optimal policy for the Supreme Court is $x_{s c}=(\hat{v}+T) / 2 \alpha$, it follows that $3 / 4-T / 4 \hat{v}>0$, or $T<3 \hat{v}$. Furthermore, as seen above, for reversal costs to be positive, $T>\hat{v}$. Thus, we obtain, $\hat{v}<T<3 \hat{v}$, for all feasible $T$. 
Lemma 1: Given that the Supreme Court knows Congress's type $\left(\alpha, T_{j}\right)$, then:

(a) the equilibrium level of Congress's utility is decreasing in $T_{j}$ and in $\hat{v}$, while it is independent of $\alpha$;

(b) the equilibrium level of the Court's utility is increasing in $T_{j}$, but it is decreasing in $\alpha$, and in the difference between the ideal point of Congress (0) and its own (SC).

The proof of (b) is straightforward from visual inspection of (5). To prove (a), observe that $\partial E U^{*} C / \partial T_{j}<0$ if and only if $T_{j}<7 \hat{v}$. From construction, however, it is clear that $\hat{v}<T<3 \hat{v}$, proving (a). Also, observe that $\partial E U^{*} C / \partial \hat{v}<0$ if and only if $T_{j}>\hat{v}$, which is satisfied for interior solutions.

2. Incomplete Information about $\alpha$ and $\mathrm{T}_{\mathrm{j}}$. Consider now the case when the Court thinks that Congress is of a particular $\left(\alpha_{\dot{p}} T_{k}\right)$ type, while Congress is actually of a different type. It is useful to explore whether Congress would benefit from changing the Court's beliefs. This exercise is performed by computing the change in Congress's expected utility that arises from changes in the Court's beliefs about Congress's preferences and reversal costs. Let $\alpha^{*}$ and $T^{*}$ be the Court's beliefs about the expected values of $\alpha$ and $T$. Because of the linearity of the Court's utility function, the Court will arrive at its decision based upon $\left(\alpha^{*}, T^{*}\right) .^{36}$ It is evident that the optimal decision is given by

$$
x^{*}=\left(\hat{v}+T^{*}\right) / 2 \alpha^{*} \text {. }
$$

Denote by $E U^{C}\left(T, \alpha \mid \alpha^{*}, T^{*}\right)$ the expected utility of Congress when the Court believes Congress is of $\left(\alpha^{*}, T^{*}\right)$ type, while Congress is of $(\alpha, T)$ type. After substituting (8) into (6), the following is obtained:

$$
\begin{aligned}
& \mathrm{EU}^{\mathrm{C}}\left(\alpha, \mathrm{Tl}^{*}, \mathrm{~T}^{*}\right)= \\
& \frac{\left(\alpha x^{*}+\vartheta-T\right)^{2}}{4 \eta}-\alpha x^{*}= \\
& \frac{\alpha^{2}\left(\nabla+T^{*}\right)^{2}-4 \alpha \alpha^{*}\left(\nu+T^{*}\right)(\nu+T)+4 \alpha^{*^{2}}(\nu-T)^{2}}{16 \alpha^{*^{2}} \nabla} .
\end{aligned}
$$

Observe that if $\alpha^{*}=\alpha$ (that is, the Court's beliefs about $\alpha$ are correct), then (9) becomes

36. If the utility function of the court were nonlinear, then the actual distribution of the Court's beliefs would factor in the calculation of its optimal policy decision. 


$$
\begin{gathered}
E U^{C}\left(\alpha, T \mid \alpha, T^{*}\right)= \\
\frac{\nu^{2}+T^{*^{2}}+4 T^{2}-12 v T-2 v T^{*}-4 T^{*} T}{16 v} ;
\end{gathered}
$$

while if $T^{*}=T,(9)$ becomes

$$
\begin{aligned}
& \mathrm{EU}^{\mathrm{C}}\left(\alpha, \mathrm{T} \mid \alpha^{*}, \mathrm{~T}\right)= \\
& \frac{\alpha\left(\alpha-4 \alpha^{*}\right)(\hat{\nu}+T)^{2}+4 \alpha^{*^{2}}(\hat{\nu}-T)^{2}}{16 \alpha^{\alpha^{2}} \hat{\vartheta}} \text {. }
\end{aligned}
$$

This section next explores the extent to which Congress can improve its position by changing the Court's beliefs about Congress's preferences and reversal costs. Lemma 2 summarizes the results.

Lemma 2: Let $\left(\alpha^{*}, T^{*}\right)$ represent the Court's beliefs about Congress's

$(\alpha, T)$. Then, for all $(\alpha, T)$ and $\left(\alpha^{*}, T^{*}\right)$ that are consistent with interior solutions, (a) increases in $T^{*}$ make Congress worse off, while (b) increases in $\alpha^{*}$ make Congress better off.

To prove the Lemma, observe, first, that changes in the Court's beliefs are translated into Congress's utility through the change in the Court's optimal action, $x^{*}$. That is, $\partial E U^{C} \partial \alpha^{*}=\partial E U^{C} \partial x^{*} . \partial x^{*} / \partial \alpha^{*}$, and $\partial E U^{C} \partial T^{*}=\partial E U^{C} \partial x^{*}$. $\partial x^{*} \partial T^{*}$. From the first part of (9), it is obtained that

$$
\frac{\partial E U^{c}}{\partial x^{*}}=\frac{2 \alpha^{2}}{4 \nu}\left(x^{*}-\frac{\partial+T}{\alpha}\right)
$$

Equation (10) implies that for $\partial E U^{C} / \partial x^{*}$ to be negative, $x^{*}<(\hat{v}+T) / \alpha$. Observe, however, that from equation (1), for the probability of reversal to be less than (or equal to) one, $x \leq(\hat{v}+T) / \alpha$, for all $x$. Thus, interior solutions imply that $\partial E U^{c} \partial x^{*}<0$. Now, to prove the Lemma, all that remains is to show that $\partial x^{*} \partial T^{*}>0$ and that $\partial x^{*} \partial \alpha^{*}<0$. Observe, first, that $\partial x^{*} \partial T^{*}=1 / 2 \alpha^{*}>0$, and that $\partial x^{*} / \partial \alpha^{*}=-\left(\hat{v}+T^{*}\right) / 2 \alpha^{* 2}<0$.

The intuition behind the Lemma is straightforward. In general, Congress prefers the Court to believe that it cares deeply about the issue (high $\alpha$ ), and that were the Court to deviate too much from Congress's ideal point, Congress could easily reverse the Court's decision (low $T$ ).

3. The Gains from Signaling. It has just been shown that if Congress makes the Court believe that Congress's expected reversal costs are low or that its marginal disutility is high, then Congress could move the Court's decision closer to its own ideal point, implying fewer expected reversals and a higher expected utility for Congress. This part now explores whether the benefits from signaling are similar across different types of Congresses, and computes the determinants of the gains from signaling. 
Consider first, for simplicity of exposition, the case when $\alpha^{*}=\alpha$, that is, the Court's beliefs about $\alpha$ are correct. If Congress could signal its expected reversal costs, its change in utility would be given by:

$$
\Delta E U^{C}=E U^{C}(\alpha, T \mid \alpha, T)-E U^{C}\left(\alpha, T \mid \alpha, T^{*}\right)=\left(T^{*}-T\right)\left[2 \hat{v}-\left(T+T^{*}\right)+4 T\right] / 16 \hat{v} \text {. }
$$

From (11), it can be seen that if $T>T^{*}$ (that is, the Court believes that Congress's reversal costs are lower than they actually are), then signaling is not useful as $\Delta E U^{C}<0 .{ }^{37}$ On the other hand, if $T<T^{*}$, then the gains from signaling are positive if and only if $2 \hat{\mathrm{v}}+3 T>T^{*}$. However, this condition is always satisfied since $\hat{v}<T<3 \hat{v}$. That is, if $T=T_{L}$ but $T^{*}=T_{H}$, then there is a gain from signaling the true $T_{L}{ }^{38}$

The following comparative statics concerning the determinants of the gains from signaling can then be derived:

Lemma 3: If $T^{*}=T_{H}$ and $T=T_{L}$, but $\alpha^{*}=\alpha$, then:

(a) $\partial \Delta E U^{C} \partial \hat{v}>0$

(b) $\partial \Delta E U^{C} \partial T_{H}>0$.

The proof of the Lemma is straightforward and is not presented here. It involves using the fact that interior solutions require that for all feasible $T, \hat{v}<T<3 \hat{v}$.

The Lemma implies, then, that for a Congress with low reversal costs, the benefits of signaling increase with the uncertainty about its own type. Observe that there are two sources of uncertainty about reversal costs: $\Delta T$ and $\hat{v}$. Higher values for either one increases the benefit from signaling its own type to a low reversal cost Congress.

Consider now a case when Congress has high reversal costs. What are its gains from convincing the Court that its reversal costs are actually low? Let

$$
\Delta E U^{C}\left(\alpha, T_{H} \mid \alpha, T_{L}\right)=E U^{C}\left(\alpha, T_{H} \mid \alpha, T_{L}\right)-E U^{C}\left(\alpha, T_{H} \mid \alpha, T_{H}\right)
$$

represent the gains from convincing the Court that Congress's reversal costs are low when, in fact, they are high. Let $\Delta=T_{H}-T_{L}$. It is straightforward that

$$
\Delta E U^{C}\left(\alpha, T_{H} \mid \alpha, T_{L}\right)=\Delta T\left(2 \hat{v}+\Delta T+2 T_{H}\right) / 16 \hat{v} \text {. }
$$

Observe that, letting $\Delta T=T_{T}-T_{L}, \partial \Delta E U^{C}\left(\alpha, T_{H} \mid \alpha, T_{L}\right) / \partial \Delta T=2\left(\hat{v}+T_{H}+\Delta T\right) / 16 \hat{v}>0$. That is, the larger the difference between the two reversal cost types, the larger the benefits from misleading the Court. Furthermore, the benefits of lying for a high reversal cost type are greater than the benefits of truthful signaling for a low reversal cost type. That is, $\Delta E U^{C}\left(\alpha, T_{H} \mid \alpha, T_{L}\right)>\Delta E U^{C}\left(\alpha, T_{L} \mid \alpha, T_{L}\right) \cdot^{39}$ The benefits from lying, however, are bounded. Recalling that $\hat{v}<T<3 \hat{v}$, it is apparent that $2 \Delta T / 16<\Delta E U^{C}\left(\alpha, T_{L} \mid \alpha, T_{L}\right)<\Delta E U^{C}\left(\alpha, T_{H} \mid \alpha, T_{\nu}\right)<10 \Delta T / 16$. Thus, if $C\left(\alpha, T_{H}\right)$ $>10 / 16 \Delta T$ but $C\left(\alpha, T_{L}\right)<2 \Delta T / 16$, then it will pay only for low reversal cost types to make the Court believe that they indeed have low reversal costs.

Thus it can be stated:

37. Observe, also, that if the cost of signaling were larger than the minimum feasible cost $(C()>$.$T -$ $\hat{v})$, then there would have been a contradiction; for signaling to take place $\Delta E U^{C}>C>T$ - $\hat{v}$, but, as the reader may find out, $\Delta E U^{C}<T-\hat{\mathrm{v}}$.

38. Equation (11) also shows that the benefits from signaling about $T$ are independent of $\alpha$, when $\alpha^{*}=\alpha$.

39. From the definition of $\Delta E U^{\mathcal{C}}$, it follows that $\Delta E U^{\mathcal{C}}\left(\alpha, T_{H} \mid \alpha, T_{\nu}\right)=\Delta T\left(2 \hat{v}+2 T_{H}+\Delta T\right) / 16 \hat{v}>$ $\Delta T\left(2 \hat{v}+2 T_{L}-\Delta T\right) / 16 \hat{v}=\Delta E U^{C}\left(\alpha, T_{L} \mid \alpha, T_{L}\right)$. 
Lemma 4: The benefits for a $\left(\alpha, T_{\nu}\right)$ type Congress from signaling its true type are lower than the benefits for a $\left(\alpha, T_{H}\right)$ type Congress from convincing the Court that it is $\left(\alpha, T_{L}\right)$.

Consider now the case when both $T$ and $\alpha$ are known only by Congress. The benefits from signaling can be derived from equation (9). Assume that if Congress signals, then the Court's posterior beliefs about Congress's reversal costs and preferences would induce the Court to make its policy choice at $x^{l}$. If Congress does not signal, assume that the Court's optimal policy would be $x^{0}$.

Then, from the first part of (9), it can be derived that

$$
\begin{gathered}
\Delta E U^{\mathrm{C}}= \\
\frac{\alpha\left(\mathrm{x}^{1}-\mathrm{x}^{0}\right)}{4 \vartheta}\left[\alpha\left(\mathrm{x}^{1}+\mathrm{x}^{0}\right)-2(\vartheta+\mathrm{T})\right]= \\
\frac{\alpha^{2}\left(\mathrm{x}^{1^{2}}-\mathrm{x}^{0^{2}}\right)}{4 \vartheta}\left(1-\frac{\vartheta+\mathrm{T}}{\frac{\alpha\left(\mathrm{x}^{1}+\mathrm{x}^{0}\right)}{2}}\right)
\end{gathered}
$$

Recall, though, that for interior solutions, preferences have to be such that for all $\left(\alpha^{l}, T^{l}, \alpha^{0}, T^{0}\right), x<(\hat{v}+T) / \alpha$. Thus, the term in large brackets in (12) is negative. As a consequence, for all $(\alpha, T)$, the benefits of signaling are positive if and only if signaling brings about a Court's decision that is closer to Congress's ideal point (the origin). That is, $\Delta E U^{C}>0 \leftrightarrow x^{1}>x^{0}$. Thus, for signaling to be an equilibrium strategy, it has to be the case that $x^{I}<x^{0}$.

Recall from Lemma 4 that if $\alpha^{*}=\alpha$, Congresses with higher reversal costs get larger benefits from mimicking low reversal cost types than the latter types get from separating themselves from higher types. The next step is to confirm that partial result for all $x^{I}<x^{0}$. From (12), it is straightforward that 


$$
\frac{\partial \Delta E U^{c}}{\partial T_{T_{1}, \alpha_{0}}}=-\alpha \frac{x^{1}-x^{0}}{20}
$$

which is positive for $x^{1}<x^{0}$.

The benefits from signaling are thus increasing in reversal costs. Therefore, if it is worth signaling (that is, if $x^{1}<x^{0}$ ), then Congresses with high reversal costs will have strong incentives to mimic the low reversal cost types. Unless costs of signaling are positively correlated with reversal costs, therefore, it will never pay for a low cost Congress to signal. The reason is clear. If it is beneficial for the low cost types to signal, then it must also be so for the high cost types. Thus, the Court would not be able to separate low from high reversal cost Congresses, and hence would pay no attention to the signaling process. If that is the case, however, then it does not pay for anyone to signal. Thus,

Lemma 5: The benefits of signaling are positive for all types of Congresses if and only if $x^{1}<x^{0}$. Furthermore, if $x^{1}<x^{0}$, then for all $\left(\alpha^{l}, \alpha^{0}, T^{0}\right)$, the benefits of signaling for a $\left(\alpha, T_{\nu}\right)$ type are lower than the benefits for a $\left(\alpha, T_{H}\right)$ type. ${ }^{40}$

A similar, although weaker, result applies to preference intensities. In particular, from (12) it follows:

$$
\frac{\partial \Delta E U^{c}}{\partial \alpha_{1 x_{1}, x_{0}}}=\alpha\left(x^{1}-x^{0}\right) \frac{\left[x^{1}+x^{0}-\frac{\hat{\nu}+T}{\alpha}\right]}{2 \nu} .
$$

First, recall that if signaling is beneficial, the first term must be negative. Thus, the sign of $\partial \Delta E U^{C} / \partial \alpha_{\mid x t, x 0}$ depends on the sign of the term in square brackets in (13). Observe that, if signaling provides the Court with Congress's true type (that is, Congress is able to separate itself from all other Congresses), then $x^{0}>x^{l}=(\hat{v}+T) / 2 \alpha$. Thus, $x^{l}+x^{0}>(\hat{v}+T) / \alpha$, and reducing $\alpha$ increases the gains from signaling. That is, if it is possible for a high $\alpha$ type to separate from all other types, then low $\alpha$ types would have an even higher incentive to signal. But if it is optimal for low $\alpha$ types to signal, then pooling would arise. To avoid pooling, signaling costs have to fall with $\alpha$, as discussed at the beginning of this section.

Thus,

Lemma 6: If (a) signaling is beneficial (that is, $x^{1}<x 0$ ), and (b) it triggers a policy $x^{I}=(\hat{\mathrm{v}}+T) / 2 \alpha_{H}$, then for all $\left(T^{t}, T^{0}\right)$ the benefits of

40. Observe, however, that if $x^{d}>x^{0}$, then the benefits from signaling increase with $T$. This result, however, does not provide much insight, as, for $x^{b}>x^{0}$, it is not worth signaling for any type. 
signaling for a $\left(\alpha_{H}, T\right)$ type of Congress are smaller than the signaling benefits for a $\left(\alpha_{L} T\right)$ type.

Lemmas 5 and 6 show the potential for pooling equilibria in this model. Since those Congress types that would allow high levels of judicial (and agency) discretion, if their types were known, are those that benefit more from misrepresenting their type to the Court by convincing it that they will allow only low departures from $P$, separation of types requires differential costs of signaling. This article's assumptions about $C(\alpha, T)$ are consistent with those needed to separate the different types, as signaling is more expensive for high $T$ and low $\alpha$ types. As a consequence, there can be different types of equilibria, some pooling and some separating. Nevertheless, since there is only one signal and there are four types of Congresses, separating equilibria will only be partially separating. That is, at least two types of Congresses will be pooled together.

For instance, if it is beneficial for a $\left(\alpha_{L} T_{H}\right)$ type to send a signal, then it is also beneficial for the other types, and hence the signal will not be informative. As a consequence, the signal will not be sent. That is, there will be complete pooling. This would happen if, for example, $C(\alpha, T)=0$ for all $T$ and $\alpha$.

Depending on the cost of signaling for the different types, and on $\Delta \alpha$ and $\Delta T$, separation could be based on the cost of reversing (that is, all $T_{L}$ types signal, while all $T_{H}$ types do not) or on the marginal disutility (that is, all $\alpha_{H}$ types signal, while all $\alpha_{L}$ do not). ${ }^{41}$ Finally, an intermediate case could arise in which three types are bunched together and only one type is separated. These results are presented in Proposition 1.

Proposition 1: With positive signaling costs, there are two basic types of equilibria: (a) total pooling with no signaling and (b) partial pooling. Furthermore, the following partial pooling cannot arise: (i) partial pooling with $\left(\alpha_{\dot{p}} T_{H}\right), j=L, H$ types signaling; (ii) partial pooling with $\left(\alpha_{L}, T_{j}\right), j=L, H$ signaling; (iii) partial pooling with $\left(\alpha_{i} T_{j}\right), i=L, H$, $j=L, H, i \neq j$ types signaling; (iv) partial pooling with $\left(\alpha_{L}, T_{L}\right)$ and $\left(\alpha_{H}, T_{H}\right)$ signaling; and (v) partial pooling with only $\left(\alpha_{L} T_{H}\right)$ signaling. Since it has already been shown that total pooling may arise, to prove the proposition it is only necessary to show conditions (i)-(v) in Proposition 1. Conditions (i)-(v) are proved by contradiction. To prove (i), assume that in equilibrium $\left(\alpha_{L} T_{H}\right)$ pools with $\left(\alpha_{H}, T_{H}\right)$ by signaling. Observing a signal, then, provides information to the Court about $T$ but not about $\alpha$. Since there are two types of $\alpha$, each has a $50 \%$ probability. As a consequence, for those who signal, $\left(\alpha^{1}, T^{1}\right)=\left[\left(\alpha_{H}+\alpha_{L}\right) / 2, T_{H}\right] ;$ for those that do not, $\left(\alpha^{0}, T^{0}\right)=\left[\left(\alpha_{H}+\alpha_{L}\right) / 2, T_{L}\right]$. The optimal Supreme Court decisions are $x^{I}=\left(\hat{v}+T_{H}\right) /\left(\alpha_{H}+\alpha_{L}\right)$ and $x^{0}=$ $\left(\hat{v}+T_{L}\right) /\left(\alpha_{H}+\alpha_{L}\right)$, implying that $x^{I}>x^{0}$. Lemma 5 , though, demonstrates that signaling provides negative benefits, resulting in a contradiction, proving (i).

41. It is clear that an equilibrium cannot exist where all $T_{H}$ signal that they are $T_{L}$, while all $T_{L}$ types do not. The reason is that if this is the case, then the Court, perceiving that only $T_{H}$ types signal, would infer that those signaling are in fact $T_{H}$ types, and hence the signaling would not be productive. 
Consider now the case when $\left(\alpha_{L} T_{H}\right)$ pools with $\left(\alpha_{L} T_{\nu}\right)$. Thus, signaling provides information about $T$ but not about $\alpha$. Thus, $\alpha^{I}=\alpha_{L} ; T^{I}=\left(T_{H^{+}}+T_{L}\right) / 2$; $\alpha^{0}=\alpha_{H} ; T^{0}=\left(T_{H}+T_{L}\right) / 2$. As a consequence,

$$
x^{1}=\frac{\vartheta+\frac{T_{H}+T_{L}}{2}}{2 \alpha_{L}} \text {, and } x^{0}=\frac{\vartheta+\frac{T_{H}+T_{L}}{2}}{2 \alpha_{H}},
$$

implying that $x^{1}>x^{0}$, and that the stated configuration of signals is not an equilibrium, proving (ii).

To prove (iii) and (iv), assume that either $\left(\alpha_{L} T_{H}\right)$ pools with $\left(\alpha_{H}, T_{L}\right)$ by signaling or $\left(\alpha_{H}, T_{\nu}\right)$ pools with $\left(\alpha_{L} T_{H}\right)$ by signaling. Then, $\alpha^{1}=\alpha^{0}$ and $T^{1}=T^{0}$, meaning that $x^{l}=x^{0}$, and, since signaling costs are positive, it cannot be beneficial to send a signal.

Finally, to prove (v), consider a situation where the only type to signal is $\left(\alpha_{L} T_{H}\right)$, while the other three types prefer not to signal. Since only one type signals, the Court can infer its identity. However, since $\left(\alpha_{L} T_{H}\right)$ has higher reversal costs and lower marginal disutility, it will always prefer to be confused with the average of the other three types. Thus, $\left(\alpha_{L} T_{H}\right)$ cannot be the only one to signal, proving the Proposition.

The following Corollary can then be stated:

Corollary 1: If only one type separates itself, then it cannot be $\left(\alpha_{L} T_{H}\right)$. If two types separate by signaling, then they can only be $\left(\alpha_{H}, T_{L}\right)$ and $\left(\alpha_{L}, T_{L}\right)$, or $\left(\alpha_{H}, T_{H}\right)$ and $\left(\alpha_{H}, T_{L}\right)$. That is, only low reversal costs or high marginal disutility types separate by signaling.

Corollary 1 provides, then, the main intuition of this article. If there is signaling, then the signaling Congress must either care substantially about the issue or must have low reversal costs. It has not been shown, though, under what conditions signaling would take place. The next sections provide some necessary conditions for signaling.

4. Some Necessary Conditions for a Signaling Equilibrium to Exist. This section shows that for signaling to be an equilibrium, both variance on the reversal costs and variance across types are necessary. That is, while uncertainty about $\alpha$ is not enough to generate a signaling equilibrium, neither is uncertainty about $T_{j}$. Thus, both random reversal costs and uncertainty about types are required. Furthermore, this article demonstrates that extreme values for the uncertainty about reversal costs eliminate any signaling equilibrium. The following Proposition provides the necessary conditions for a signaling equilibrium to occur:

Proposition 2: For a signaling equilibrium to occur, it is necessary that: (a) $0<\hat{v}<T_{L}$; (b) the probability that $T=T_{j}, j=L, H$, be positive; and (c) signaling costs increase in $T$ and decrease in $\alpha$.

The proposition is shown by contradiction. Point (c) was previously discussed, and thus will not be proven here. For points (a) and (b) assume that 
$\hat{\mathrm{v}}=0$. Further assume that it was optimal for $\left(\alpha_{H}, T_{L}\right)$ types to signal and for no one else. Thus, $x^{l}=P+T_{L} / \alpha_{H}$. Congress's utility, though, will equal $-\alpha_{H} T_{L} / \alpha_{H}=-T_{L}$, which is the same value that would result from reversing the Court. Thus, signaling does not provide a better outcome for Congress than reversing. If, however, a $\left(\alpha_{H}, T_{\nu}\right)$ type would not signal its own type, then neither would any other type. Now assume that $\hat{v}=T_{L}$. Again, a $\left(\alpha_{H}, T_{L}\right)$ type considering whether to signal will find that if it signals its own type, its utility will be $-T_{L}$, the same as it would obtain if it did not signal and later on reversed the Court. Thus, if such a type does not find it worthwhile to signal its own type, then no other type will, as no type will be able credibly to claim to be $\left(\alpha_{H}, T_{\mathcal{L}}\right)$. Thus (a) has been shown.

To show (b), consider a situation where $T=T_{H}$, with probability one. Thus, Congresses differ only on their $\alpha$ 's. If the Court knows Congress's type, then it will set $x=T / \alpha$. If the Court is uncertain about the type, it will pick either $T / \alpha_{H}$ or $T / \alpha_{L}$, depending on which gives it a higher expected utility. While $x=T / \alpha_{H}$ will never be reversed, $x=T / \alpha_{L}$ will be reversed with probability 0.5 . Thus, it is straightforward that the Court will pick $T / \alpha_{L}$ if and only if $2 \alpha_{L}<\alpha_{H}$. Assume this to be the case. Then, if a $\alpha_{H}$ type does not signal, its utility is given by $-T$ (as it will reverse the Court's decision). If it signals, the Court will pick $T / \alpha_{H}$, giving Congress a level of utility equal to $-T$. Thus, there are no gains from signaling for the $\alpha_{H}$ type; no other type will send such a signal either, showing the Proposition.

The Proposition, then, provides basic conditions for signaling equilibria to develop. The main insight of the Proposition is that there has to be substantial uncertainty about reversal types, but not too much. As discussed above, there are two sources of uncertainty: types and the randomness in reversal costs. Proposition 2 shows that, in our framework, both sources of uncertainty are important. Recall that the term $v$ relates to the volatility over time of the reversal costs of Congress. If the volatility is extreme, perhaps because of high turnover among the members, then there will be no separating equilibrium and, as a consequence, there is no point in the Court trying to ascertain the relevant legislative history. On the other hand, moderate uncertainty may trigger signaling, and thus prompt the Court to consider the relevant legislative history, since such history may be informative about congressional preferences.

5. An Example of an Equilibrium with Partial Pooling. This section examines a separating equilibrium where only $\left(\alpha_{H}, T_{\nu}\right)$ types signal. This is a particularly interesting example, as it involves a Congress that cares deeply about the issue and is quite cohesive. In this case, then, the pivotal member of Congress cares greatly and can also obtain support relatively easily from other committees and members of Congress in order to pass remedial legislation. If the Court could separate this type of Congress from all others, both the Court and this type of Congress would be much better off. 
Assume that $\alpha_{L}=.8, \alpha_{H}=1, T_{L}=.8, T_{H}=1, \hat{v}=.6$, and let $C(\alpha, T)=T(3$ $\alpha) / 10-.07$. Finally, let each of the four types occur with equal probability. These assumptions satisfy the different requirements previously discussed.

For only $\left(\alpha_{H}, T_{\nu}\right)$ to signal, the following four equations have to be satisfied:

$$
\begin{aligned}
& \Delta E U^{C}\left(\alpha_{H}, T_{L} \mid \alpha^{l}, T^{l}, \alpha^{0}, T^{0}\right)>C\left(\alpha_{H}, T_{L}\right) \\
& \Delta E U^{C}\left(\alpha_{L} T_{L} \mid \alpha^{l}, T^{l}, \alpha^{0}, T^{0}\right)<C\left(\alpha_{L} T_{L}\right) \\
& \Delta E U^{C}\left(\alpha_{H}, T_{H} \mid \alpha^{I}, T^{l}, \alpha^{0}, T^{0}\right)<C\left(\alpha_{H}, T_{H}\right) \\
& \Delta E U^{C}\left(\alpha_{L}, T_{H} \mid \alpha^{1}, T^{l}, \alpha^{0}, T^{0}\right)<C\left(\alpha_{L}, T_{H}\right),
\end{aligned}
$$

where, for example, equation (14a) says that for a $\left(\alpha_{H}, T_{L}\right)$ Congress, the benefits of signaling $\left(\triangle E U C C^{C}(\circ)\right)$ exceed its costs $(C(\circ))$. Observe that the benefits of signaling depend on both Congress's type-being $\left(\alpha_{H}, T_{L}\right)$ in equation (14a) - and on the changes that signaling brings in the Court's beliefs from $\left(\alpha^{0}, T^{0}\right)$ to $\left(\alpha^{1}, T^{1}\right)$. The set of equations (14), then, suggests that it pays to signal only for Congresses that care a great deal about the issue and have low reversal costs.

Substituting the values for the different parameters, (14a)-(14d) can be replaced by:

$$
\begin{aligned}
& \Delta E U^{C}\left(\alpha_{H}, T_{L} \mid \alpha^{l}, T^{l}, \alpha^{0}, T^{0}\right)=.0935>C\left(\alpha_{H}, T_{L}\right)=.090 \\
& \Delta E U^{C}\left(\alpha_{L} T_{L} \mid \alpha^{1}, T^{l}, \alpha^{0}, T^{0}\right)=.0943<C\left(\alpha_{L}, T_{H}\right)=.106 \\
& \Delta E U^{C}\left(\alpha_{H}, T_{H} \mid \alpha^{1}, T^{l}, \alpha^{0}, T^{0}\right)=.1243<C\left(\alpha_{H}, T_{H}\right)=.130 \\
& \Delta E U^{C}\left(\alpha_{L} T_{H} \mid \alpha^{l}, T^{l}, \alpha^{0}, T^{0}\right)=.1189<C\left(\alpha_{L}, T_{L}=.150 .\right.
\end{aligned}
$$

Equations (15) satisfy all the requirements for type $\left(\alpha_{H}, T_{L}\right)$ to be the only one that would signal.

\section{III}

\section{CONCLUSION}

This article provides a positive theory of legislative intent. The theory explains two empirical puzzles: first, why Congress sometimes legislates in a very vague form, allowing substantial discretion in the interpretation to the agencies and the Court, while at other times it passes very specific pieces of legislation, substantially restricting agency and judicial discretion; and, second, why the Court seems to look at legislative intent in making its decisions. The theory suggests that these two puzzles are not unrelated. Both are the results of the costs of writing specific pieces of legislation and of reversing the Court, as well as of a lack of information about Congress's preferences and reversal costs. Since writing specific pieces of legislation is costly, it will not always be worthwhile for members of Congress to express in great detail what policy they would like the agencies and the Court to achieve. In particular, if the cost of reversing agency and judicial decisions is very high, or if the relevant members of Congress are relatively indifferent about the actual policies that will be taken, or if both of these conditions apply, then it will not pay for Congress to specify ahead of time what policies should be undertaken. On the other hand, if Congress specifies the policies, then it provides a signal that its cost of reversing is quite low, or that it has strong preferences about policies, or that both are true. 
For signaling to be relevant (that is, for specific legislation to be drafted originally), however, the Court cannot have full information about Congress's preferences and reversal costs. If that were the case, then all pieces of legislation would be vague, as there would be no need to specify what is already well known. Once preferences and reversal costs are uncertain, however, the Court may look at Congress's actions and extract, albeit partially, Congress's characteristics. If Congress passes a specific law, then the optimal decision for the Court will be closer to the ideal point of Congress than if Congress were to pass a vague piece of legislation.

It is important to note that specific legislation per se is not enough to guarantee judicial cooperation. Even if the statute is written in such a way as to prescribe a particular action in almost every contingency, the Court still has the ability to ignore these prescriptions. Only the perceived threat of congressional response induces the Court to follow the wishes of the enacting Congress. Those who suggest that forcing Congress to write more specific legislation, in the common sense of a longer and more precise statute, will solve the legislative intent/statutory interpretation dilemma fail to recognize the important strategic considerations underlying the relationship between Congress and the Court. To the extent that legislative history and other supplementary materials can provide as informative a signal as can more precise statutory language, these materials may be a preferable source of that signal, as they can be provided at lower cost. Thus, if a separating equilibrium exists simply with the costs associated with supplementary material, then there may not be a need for specific legislation to be written for signaling purposes. Furthermore, as issues become more complex, the costs of specific legislation may increase to the point at which no signaling may actually develop. In such a case, supplementary materials may be all that is needed to transmit information about legislative intent.

This article has highlighted and discussed the role of issue salience and uncertainty about reversal costs. Clearly, another type of uncertainty to be examined in the future concerns the basic policy preferences of the pivotal member of Congress. That is, the Court may be uncertain about the value of $P$. In this case, statutory language may play a more important role, as actually voting on a provision may reduce the uncertainty about policy preferences more than materials that have not been subject to a majority vote. It is important to note, however, that if such a vote provides a signal to the Court, members of Congress may find it in their interests to vote strategically, thus obfuscating the true value of $P$.

A major implication of this article is that the Court would like to promote behavior by Congress that facilitates separation of types. By so doing, the Court increases the amount of information it has about potential congressional responses to its own decisions. This suggests that canons of statutory interpretation will be biased toward congressional activities that are neither so trivial as to be pursued by every member of all Congresses, nor so costly as to be almost impossible to undertake by most Congresses. In this sense, the standard view of judicial canons of statutory interpretation seems to fit this article's framework. 
Justices first look to the wording of the actual statute (the most costly signal of all), then to committee reports, and finally to legislative history (the poorest signal). An interesting topic left for future research is the examination of the different canons of statutory interpretation in light of the factors identified in this paper.

The model suggests a dynamic theory of statutory interpretation. If the members of Congress or the preferences of those members change substantially over time, then the amount of useful information to be gleaned from the legislative history of an old statute is very small, implying that the Court should not pay much attention to it. This is generally consistent with the dynamic approach suggested by Eskridge ${ }^{42}$ and is supported by the normative arguments of Judge Easterbrook.

If the members of the Ninety-third Congress reassembled next month and declared their legislative meaning, the declaration would have absolutely no force. This rump body would get no greater power by claiming that its new "laws" were intimately related to, and just filled gaps in, its old ones. ${ }^{43}$

After all, at the end of any legislative session, "[any] unaddressed problem is handled by a new legislature with new instructions from the voters." 44 Therefore, in addition to the model's suggestion that a rational Court should focus on the legislative history of the enacting legislature only to the extent that such materials are likely to reflect the preferences of important coalitions in the current Congress, there are important constitutional reasons to prohibit the wishes of a long since departed Congress from holding sway over current public policy.

The conclusion just made does suggest some instances in which original legislative history should play a role in statutory interpretation. First, when Congress has consistently failed to update a statute, in spite of opportunities to do so, Congress may be construed to be endorsing the existing statute. Here, the Court would be wise to examine the legislative history of attempts to update the statute, even when such attempts resulted in no new statute. If Congress exerts substantial effort in resolving a policy dilemma, only to reaffirm the status quo, the Supreme Court can still infer something about the preferences of the current Congress from its efforts. Therefore, lack of a new statute should not preclude statutory interpretation. To the extent that members of Congress refer to pre-existing legislative history, those materials may be productively examined by the Court to infer the preferences of current members from the activities of like-minded predecessors.

When drafting new legislation, members of Congress may refer to the process of generating an old, related statute to suggest that factors motivating the

42. William N. Eskridge, Dynamic Statutory Interpretation, 135 U. PA. L. REV. 1479 (1987).

43. Easterbrook, supra note 3, at 549.

44. Id. at 548 . 
drafters of the old statute are also at work now. Again, to the extent that the Court has reason to believe that this new Congress resembles the old one, reference to the old statute in constructing the new one will provide information to the Court about how this new Congress will respond to the Court's interpretation of both the old and new statutes. The Court must be careful in this endeavor, however, in that original legislative history should be inferred to reflect current congressional preferences only to the extent that it becomes part of the history of the new legislation. This point applies equally to the prior example of failed attempts to update a statute. To the extent that materials supplementary to a new statute contradict what the Court could infer about the preferences of the Congress that enacted an old related statute (from that statute's own materials), the signal from the old Congress should be ignored in favor of that from the new one. The main thrust of this argument is that related legislative history, subsequent to enactment, should not be ignored by the Court. In fact, it should take precedence. Thus, the results of the model should encourage the practice of examining subsequent legislative history, a practice that has recently come under fire.

At least one caveat is in order here. One role traditionally ascribed to the judiciary in the U.S. system is defender of the stability and legitimacy of the governing regime. Free from short-run electoral pressures, Justices can and do place greater weight on long-term issues, recognizing the reliance of the public on a stable body of laws to guide its behavior. Therefore, it is important to Justices that statutes have "meaning," in the sense of controlling behavior independent of the whims of legislators and presidents elected for relatively short terms. The extent to which such concerns motivate judicial behavior is an open question, depending upon what one believes Justices "want," an issue that is very far from being resolved. While this article does not explicitly consider how the value of statutes will affect the behavior of the Supreme Court, such consideration would not interfere with the fundamental premise of the enterprise. The Supreme Court engages in statutory interpretation in the shadow of, and in anticipation of, potential congressional response. While it is possible that the Court's determination of the optimal interpretation may be shaped, in part, by a desire to hold true to the original statute, it is foolhardy for the Court to behave as a "naive textualist." ${ }^{\text {" }}$ Doing so will only result in the original statute being overturned more frequently by Congress, a result that can hardly be considered to increase stability and legitimacy.

45. We use this term as defined by Ferejohn and Weingast: “ $A$ naive textualist interprets the legislation as close as possible to that desired by the enacting legislature. We call this 'naive' because such a court does not take into account the political consequences of its decisions, i.e., whether its interpretations are politically viable [in other words, whether they will not be overturned by congress]." Ferejohn \& Weingast, supra note 15 , at 268 